Anagh A. Sahasrabuddhe

Kojo S. J. Elenitoba-Johnson
Role of the ubiquitin proteasome system in hematologic malignancies
Authors' address

Anagh A. Sahasrabuddhe ${ }^{1}$, Kojo S. J. Elenitoba-Johnson ${ }^{1}$

${ }^{1}$ Department of Pathology, University of Michigan, Ann Arbor, MI, USA.

Correspondence to:

Kojo S. J. Elenitoba-Johnson

Department of Pathology

University of Michigan

2037 BSRB 109 Zina Pitcher Place

Ann Arbor, MI 48109, USA

Tel.: +1 7346154388

Fax: +1 7346159666

e-mail: kojoelen@umich.edu

Acknowledgements

This work was supported in part by NIH grants R01 DE119249, and R01 CA136905 to KSJ E-J. The authors declare no conflicts of interest.

This article is part of a series of reviews covering Hematologic Malignancies appearing in Volume 263 of Immunological Reviews.
Immunological Reviews 2015

Vol. 263: 224-239

(C) 2014 John Wiley \& Sons A/S. Published by John Wiley \& Sons

Ltd

Immunological Reviews

0105-2896
Summary: Ubiquitination is a post-translational modification process that regulates several critical cellular processes. Ubiquitination is orchestrated by the ubiquitin proteasome system (UPS), which constitutes a cascade of enzymes that transfer ubiquitin onto protein substrates. The UPS catalyzes the destruction of many critical protein substrates involved in cancer pathogenesis. This review article focuses on components of the UPS that have been demonstrated to be deregulated by a variety of mechanisms in hematologic malignancies. These include E3 ubiquitin ligases and deubiquitinating enzymes. The prospects of specific targeting of key enzymes in this pathway that are critical to the pathogenesis of particular hematologic neoplasia are also discussed.

Keywords: ubiquitin-proteasome system, hematologic malignancy, E3 ligase, deubiquitinases

\section{The ubiquitin proteasome system}

The ubiquitin proteasome system (UPS) is the major degradation machinery that controls the abundance of critical cellular regulatory proteins through a stepwise cascade consisting of a ubiquitin activating enzyme or UBA (E1), ubiquitin conjugating enzymes or UBC (E2), and ubiquitin ligase (E3) enzymes. The ubiquitin ligases are terminal enzymes that activate and transfer ubiquitin through a thioester linkage for ultimate transfer of ubiquitin to the $\varepsilon$-amino group of a lysine $(\mathrm{K})$ residue on the substrate or the amino-terminus of a polypeptide $(1,2)$. After the linkage of ubiquitin to the protein substrate, a polyubiquitin chain is usually formed in which the C-terminus of each ubiquitin unit is linked to a specific lysine residue (most commonly Lys ${ }^{48}$ ) of the previous ubiquitin if the substrate is destined for degradation. Fig. 1 illustrates a schematic of the series of reactions mediated by the cascade of enzymes in the ubiquitin-proteasome system for degradation of a target substrate. In humans, there are two E1 proteins, approximately 30 E2 proteins, and hundreds of E3 ligases $(3,4)$. The E3 ligases confer substrate specificity to the UPS. The E3

(C) 2014 John Wiley \& Sons A/S. Published by John Wiley \& Sons Ltd 


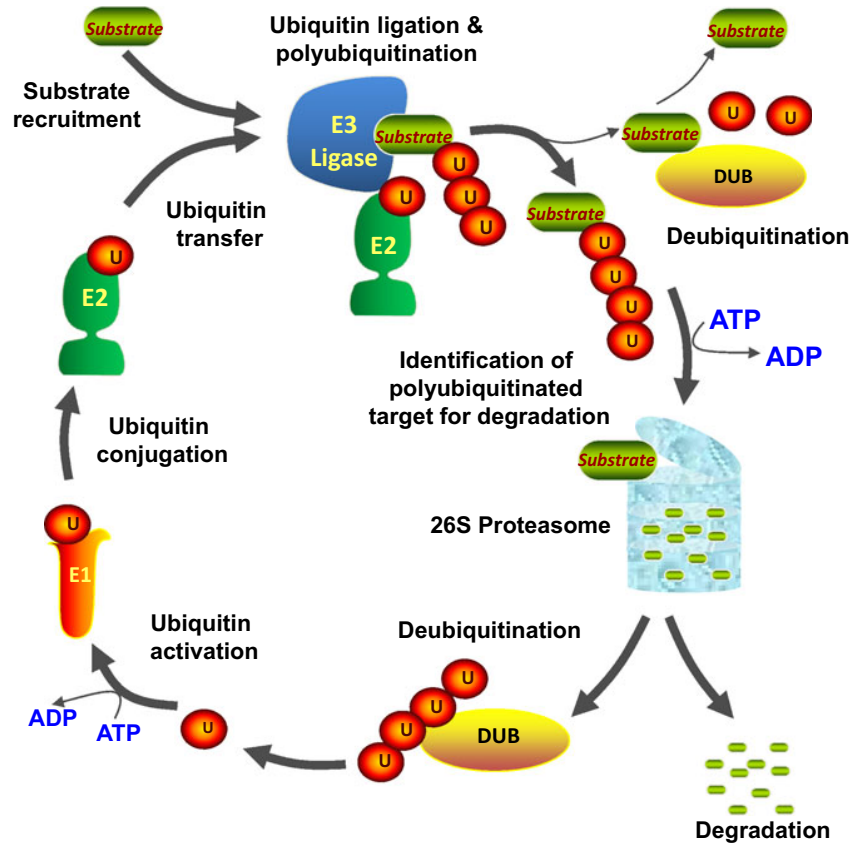

Fig. 1. Illustration of the series of reactions mediated by the cascade of enzymes of the ubiquitin-proteasome system. Initially, in the ubiquitin activation reaction, the 76 amino acid ubiquitin molecule is activated by its transfer to E1 enzyme in an ATP-dependent manner. In the next step, this activated ubiquitin is then transferred from E1 enzyme to the E2 enzyme in ubiquitin conjugation reaction. The E2 enzyme then interacts with E3 ligase and come in close proximity of substrate allowing for the ubiquitin transfer to the substrate. This process is repeated several times with the Lys of the ubiquitin protein serving further as the substrate to generate polyubiquitin chain. Once a chain of K48 linked four or more ubiquitin molecule is formed onto the substrate protein, the substrate is then targeted for degradation by the $26 \mathrm{~S}$ proteasome. However, before undergoing degradation by $26 \mathrm{~S}$ proteasome, the polyubiquitination signal from the substrate can be reversed by deubiquitinase enzyme thereby protecting substrate from degradation. The E3 ligases and deubiquitinase enzymes are important because they mediate target substrate specificity during this process of proteasomal degradation.

ubiquitin ligases regulate many biological processes through timely ubiquitination and degradation of many cellular proteins responsible for gene transcription/repression, receptor endocytosis, intracellular trafficking, and response to extracellular signals, cell cycle progression, and apoptosis $(5,6)$. Perturbation of the timely turnover of regulatory proteins disturbs the intricate balance of signaling pathways and ensuing cellular homeostasis contributing to the multistep process of malignant transformation and tumorigenesis. In this context, the involvement of E1 in cancer has not been described, and only a few reports have linked E2 deregulation to cancer development. However, increasing evidence indicates that deregulation of E3 ligase often results in development of several types of malignancies including hematologic malignancies $(4,7)$. In this review, we discuss the spectrum of E3 ligases whose substrate targeting functions are noted to be deregulated by multiple mechanisms in hematopoietic malignancies.

Ubiquitin ligases may exist as multi-subunit complexes or as a single protein unit, and they may possess one or more critical domains that facilitate ubiquitination such as RING domain (really interesting new gene), HECT domain (homologous to E6-AP carboxy-terminus), or U-box domain (8). Hence, based on structural configuration and subunit composition these ligases are classified into several groups such as HECT-type, single RING-type and multi-subunit RING type such as SCF-type (Skp1-Cullin 1-F box protein), ECV type, APC/C (anaphase-promoting complex/cyclosome), and Cullin4 type (9). While, RING and U-box domain containing E3 ligases act as a scaffolding protein to recruit substrate and E2 enzymes in close proximity for ubiquitin transfer, HECT type E3 ligases receive ubiquitin from an E2 enzyme and can directly catalyze the conjugation of the ubiquitin molecule onto the substrate protein. Fig. 2 depicts the schematic representation for the mechanism of ubiquitin transfer from an E2 enzyme to substrate among multi-subunit RING type, single subunit RING type and HECT type E3 ligases.

\section{E3 ubiquitin ligases deregulated in hematologic malignancies}

Many ubiquitin ligases have been implicated in the pathogenesis of hematologic malignancies (5, 10-19). Aberrant proteolysis of important regulatory proteins whose precise and timely function is required for successful progression of cell division cycle, transcriptional regulation, DNA damage response and apoptosis significantly contribute to neoplastic transformation $(4,20-23)$. Based on the functional effects conferred by degradation of critical substrates, E3 ligases have been assigned functions as oncogenes or tumor suppressor $(9,24)$. However, some of E3 ligases switch their function as oncogene or tumor suppressor based on context, timing, localization, and cell lineage (24). Many ubiquitin ligases are mutated, overexpressed or deleted in hematologic malignancies contributing to the pathogenesis of the diseases through accumulation or excessive degradation of their substrates which perform critical functions that regulate proper hematopoietic cell growth and differentiation. Fig. 3 illustrates the E3 ligases and deubiquitinases (DUBs) that harbor genetic aberrations in hematologic cells.

These E3 ligases along with associated E2 enzymes function as multisubunit complexs. The cullin-RING E3 


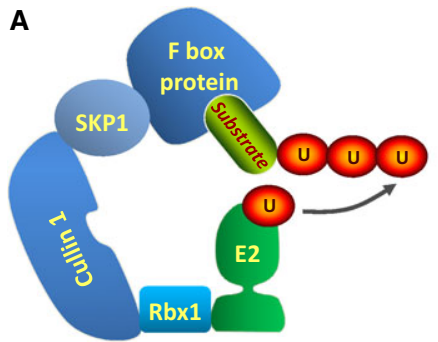

B

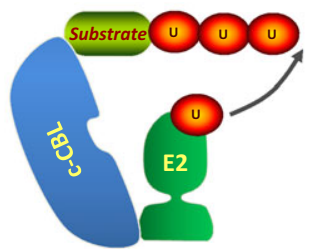

C

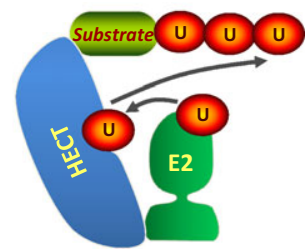

Fig. 2. The complex composition and mechanism of action of E3 ligases that are reported to be genetically altered in hematologic malignancies. (A) SCF (SKP1-CUL1-F-box protein) type E3 ligase complex. The SCF [SKP1 (S phase kinase associated protein 1) CUL1 (Cullin 1) RBX1 (Ring box 1)] core complex recruits substrates through interchangeable substrate specific F box proteins. RBX1 binds to the E2 enzyme while $\mathrm{F}$ box protein binds to the target substrate. (B) c-CBL E3 ligase complex. CBL is a multi-domain protein. A tyrosine kinase-binding domain (TKBD) is connected to the RING domain via a linker-helix region. The RING domain binds the E2 enzyme and TKBD bind the substrate. (C) HECT type E3 ligase complex. In case of (A) and (B) which are RING type E3 ligase, the E2 enzyme interacts with E3 ligase to come in close proximity of substrate which has also interacted with E3 ligase at the different region and transfer ubiquitin molecule to the substrate. While in case of HECT E3 ligase, the E2 enzyme transfer ubiquitin molecule to E3 ligase and then E3 ligase directly transfer the ubiquitin molecule onto the target substrate.

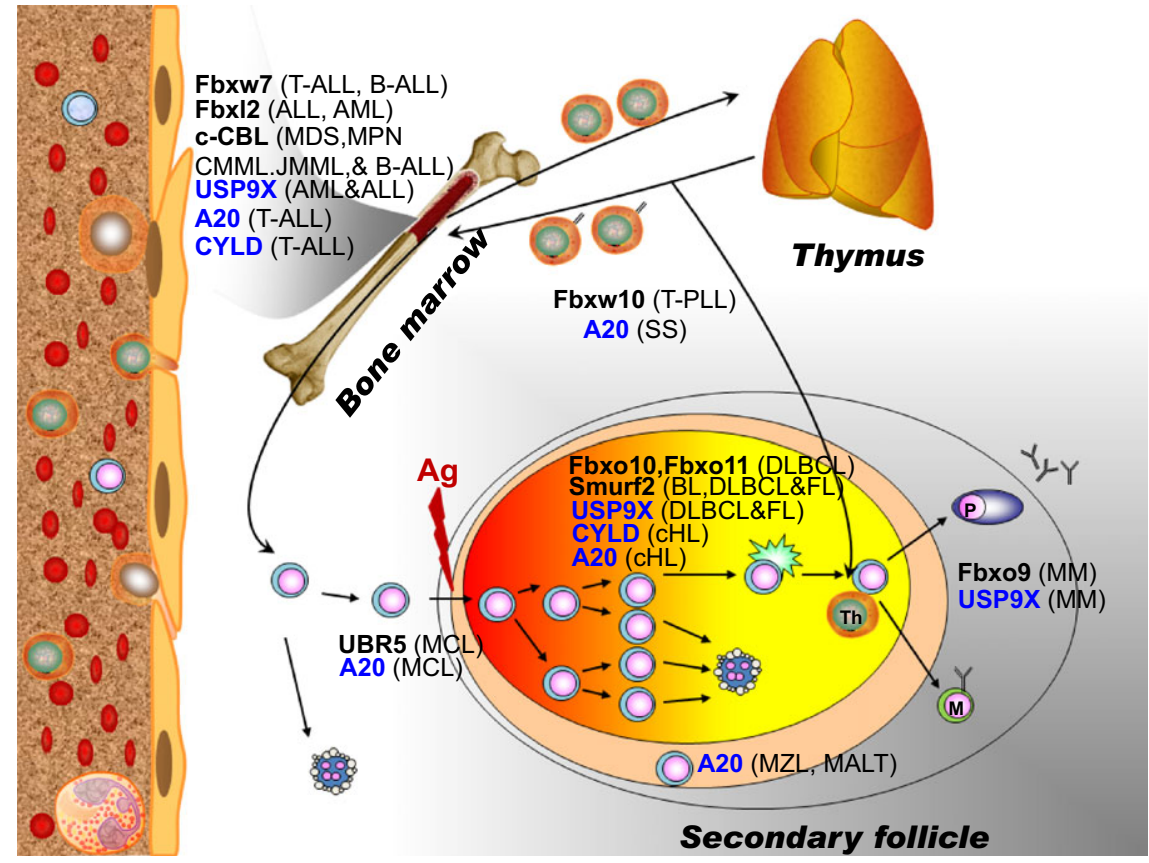

Fig. 3. Illustration of different $\mathrm{E} 3$ ubiquitin ligases and deubiquitinases that are reported to harbor genetic aberrations altering their function in hematologic malignancies. In this illustration, the relevant ubiquitin ligases and deubiquitinases that are genetically altered through mutation/deletion or overexpression are shown along the line of the hematologic cell maturation program.

ubiquitin ligase complexs (CRLs) comprises the largest known class of multicomponent-RING E3 ligases and target a wide array of substrates critical for cellular homeostasis (Fig. 2). CRLs are composed of a cullin protein scaffold that binds a RING protein to recruit an E2 protein at one end as well as utilize specific adapters that associates with distinct class of substrate receptors. Substrate receptors interact with and present substrates to the E2-CRL complex for polyubiquitination followed by degradation through $26 \mathrm{~S}$ proteasome.
Among all cullin-RING complexes, Cullin1-mediated SCF complexes are most extensively characterized.

The SCF type ubiquitin ligase is a multiprotein complex with three core components: RBX1 (Ring finger protein 1), CUL1 (Scaffold protein), and SKP1 (adapter protein), and one variable component $\mathrm{F}$ box protein (substrate receptors) that associates with a complex via binding to SKP1 through its F box motif. Substrate selection is generally achieved through interaction of the substrate-interaction domain of $\mathrm{F}$ 
box protein with a target protein destined for degradation. So far, $69 \mathrm{~F}$ box proteins have been identified in humans, and they can be classified into three categories: those with WD 40 repeats (FBXW), leucine-rich repeats (FBXL), or other domain-containing proteins (FBXO) $(25,26)$. The SCF complex utilizes these 69 different $\mathrm{F}$ box proteins as substrate receptors to form 69 distinct SCF complexes. The following section highlights the selected E3 ligase components that are reported to be genetically altered and thus contribute to the development of hematologic malignancies. First, the hematologic malignancies harboring genetic aberrations within multi-subunit RING-type SCF E3 ligase substrate receptor $\mathrm{F}$ box proteins are discussed starting from FBXW type, FBXL type and FBXO type. Next, hematologic malignancies harboring genetic aberrations in single subunit RING type CBL E3 ligases are discussed. Finally, the hematologic malignancies harboring genetic aberration within HECT type E3 ligases are discussed (Table 1).

\section{Fbw7}

Fbw7 is an F box-containing protein that has F box domain interacting with the E3 ligase complex through SKP1 (adapter protein) and eight WD40 repeats that interact with phosphorylated target substrates. Frequent inactivation of Fbw7 by deletions or point mutations occurs in neoplasia of diverse hematologic malignancies such as T-cell acute lymphocytic leukemia (T-ALL) and B-cell acute lymphoblastic leukemia (B-ALL) $(16,17,19,27)$. Specifically, the most frequent Fbw7 mutations are identified in T-ALL (approximately 30\%) and cholangiocarcinomas (approximately 35\%) (28). Commonly the missense mutations of Fbw7 occurring at R465C, R479Q, and R505C within WD40 repeats 3 and 4 (from Fbw7 $\alpha$ ) diminish its capacity to recruit substrates to the E3 ligase complex by loss of interaction (19). Fbw7 substrates have been demonstrated to play critical roles in cell cycle progression, differentiation, and metabolism and function as dominant oncogenes. Therefore, Fbw7 is believed to function as tumor suppressor due to the negative regulation of its substrate oncoproteins. Collectively, the studies indicate that Fbw7 mutations can disrupt targeted proteolysis of substrates responsible for cell growth and proliferation promoting oncogenesis.

\section{Fbxwl0}

Another WD40 repeat domain containing $\mathrm{F}$ box protein, Fbxw10, also known as HREP, Fbw10, SM25H2, and

Table 1. Genetic aberration of E3 ligases and deubiquitinases identified in hematologic malignancies

\begin{tabular}{|c|c|c|c|}
\hline & Genetic aberration identified & Malignancy associated & References \\
\hline Fbxw7 & $\begin{array}{l}\text { Trisomy, Insertion/Deletion (Indel), Frame shift, Missense including } \\
\text { R465H/C, R479Q, R505C/L, H420Y, H470P }\end{array}$ & T-ALL, B-ALL, CLL & $(16,17,19,27,165)$ \\
\hline Fbxll (Skp2) & Overexpression, gene amplification & Various NHL & $(14,30,31)$ \\
\hline $\mathrm{Fbxl2}$ & Expression down-regulation & $A M L, A L L$ & $(10)$ \\
\hline Fbxoll & $\begin{array}{l}\text { Frame shift mutations and Deletions including Y I 22C, } \Delta 665-675 \mathrm{fs} \text {, } \\
\text { D333fs, } \mathrm{K} 63 \mathrm{IQ} / \mathrm{N} \text { and G600E }\end{array}$ & $\mathrm{BL}$ and $\mathrm{DLBCL}$ & $(12)$ \\
\hline $\begin{array}{l}\text { Smurf2 } \\
\text { UBR5 }\end{array}$ & $\begin{array}{l}\text { Expression down-regulation } \\
\text { Insertion/Deletions, Frame shift mutations, Missense, and splice site } \\
\text { mutations including W2725* and HI932P }\end{array}$ & $\begin{array}{l}\mathrm{BL} \text { and } \mathrm{DLBCL} \\
\mathrm{MCL}\end{array}$ & $\begin{array}{l}(18) \\
(15)\end{array}$ \\
\hline CYLD & Deletions and expression downregulation & $\mathrm{cHL}$ and $\mathrm{T}-\mathrm{ALL}$ & $(123,170)$ \\
\hline A20 & $\begin{array}{l}\text { Deletions, Frame shift mutations, Promoter hyper-methylation and } \\
\text { Nonsense mutations including 532*, 750*, W85*, E452*, and } \\
\text { Missense mutations including A753T, E75 I K, Q737K, and M788I }\end{array}$ & $\begin{array}{l}\text { DLBCL, MCL, MZL, MALT, } \\
\text { HL, and T-ALL }\end{array}$ & $(|33-| 4|| 7 \mid)$, \\
\hline
\end{tabular}

c-HL, classical Hodgkin's lymphoma; NHL, non-Hodgkin's lymphoma, FL, follicular lymphoma; DLBCL, diffuse large B-cell lymphoma; MCL, mantle cell lymphoma, MM, multiple myeloma; AML, acute myeloid leukemia; ALL, acute lymphoid leukemia; MDS, myelodysplastic syndrome; MPN, myeloproliferative neoplasm, CMML, chronic myelomonocytic leukemia; JMML, juvenile myelomonocytic leukemia; CML, chronic myelogenous leukemia; T-PLL, T-cell pro-lymphocytic leukemia; SS, Sezary syndrome. 
SM2SH2, has been reported to harbor frame shift and nonsense mutations in T-cell prolymphocytic leukemia (T-PLL) (29). Overall, very little is known about this F box protein's function and the biological consequences of its inactivation. Identification of substrates targeted by this $\mathrm{F}$ box protein may further provide significant insights on its role in the pathogenesis of T-PLL.

\section{Fbxll}

The Fbxl1, also commonly known as S-phase kinase-associated protein 2 (SKP2), is a leucine-rich domain containing $\mathrm{F}$ box protein. SKP2 overexpression was associated with poor prognosis in human lymphoma patients $(30,31)$. The oncogenic potential of SKP2 has also been shown in transgenic mouse models of $\mathrm{T}$ lymphoid lineage where expression of SKP2 with N-ras developed T-cell lymphoma with shorter latency and decreased survival (14). SKP2 is a major regulator of cell cycle progression through degradation of cell cycle intermediates. The development and progression of several types of malignancies are fundamentally associated with deregulated cell cycle control. Cell cycle progression is precisely regulated by timely synthesis and degradation of cell cycle regulatory proteins: cyclin-dependent kinases (CDK1, CDK2, CDK4, and CDK6), their essential activating coenzymes, the cyclins (cyclin A, B, D, and E), the CDKinhibitory proteins (CDKIs), and their associated signaling networks that control their function via post-translational modifications. The abundance of these intermediates during the different phases of cell division cycle is tightly controlled by UPS $(4,32)$.

Cell cycle progression is principally driven by cyclins and their respective cyclin-dependent kinase (CDK) complexes in different phases of cell cycle. Cyclin-dependent kinase inhibitors (CKIs) are the critical regulators of cyclin-CDK activities. CKIs function by inhibiting CDK activity and promoting cell cycle arrest and/or delaying the response to anti-mitogenic stimuli. These CKIs fall into two families: the INK4 inhibitors and CIP/KIP inhibitors. There are four known INK4 family members: p16 ${ }^{\text {INK4A }}, \mathrm{p} 15^{\text {INK4B }}$, $\mathrm{p} 19^{\mathrm{INK} 4 \mathrm{D}}$, and $\mathrm{p}^{18 \mathrm{INK} 4 \mathrm{C}}$. The three mammalian $\mathrm{CIP} / \mathrm{KIP}$ CKIs- namely p2 $1^{\mathrm{CIP} 1}, \mathrm{p} 27^{\mathrm{KIP} 1}$ and $\mathrm{p} 57^{\mathrm{KIP} 2}$ play different role in cell cycle regulation $(32,33) . \mathrm{SCF}^{\mathrm{SKP} 2} \mathrm{E} 3$ ligase complex targets all three CKIs: p2 $1^{\mathrm{CIP} 1}, \mathrm{p} 27^{\mathrm{KIP} 1}$, and $\mathrm{p} 57^{\mathrm{KIP} 2}$ at different stages of cell cycle for degradation (34-39). However, p $27^{\mathrm{KIP} 1}$ seems to be the principal target of SKP2 as the prominent phenotypes apparent in SKP2 ${ }^{-/-}$mice including nuclear enlargement, polyploidy and an increased number of centrosomes, that are linked to over-replication of chromosomes and centrosomes. These phenotypic aberrations disappear in Skp2 $2^{-/-} \mathrm{p} 27^{-/-}$double mutant mice $(40,41)$. Degradation of $\mathrm{p} 27^{\mathrm{KIP} 1}$ by SKP2 would promote cell transition from $\mathrm{G} 1$ to $\mathrm{S}$ phase, and therefore increased expression of SKP2 would result in a failure to regulate the G1/S checkpoint. Since SKP2 targets p2 $7^{\mathrm{KIP} 1}$ and other CKIs for degradation, it can be considered an oncogene. In addition to CKIs, SKP2 also targets p130, cyclin A, cyclin D1, free cyclin E, ORC1, CDK9, MYC, Myb, SMAD4, RAG2, UBP43, FOXO1, and papillomavirus E7 protein, suggesting its crucial role in governing many key cellular processes (42).

\section{$\mathrm{Fbx} 12$}

Similar to Fbxl1, another Fbxl family member Fbxl2 E3 ubiquitin ligase recruits cyclin D2 for ubqiuitination and degradation in normal B lymphocytes and leukemic B cells. An inverse correlation has been observed between Fbxl2 and cyclin D2 in primary samples of human acute myeloid leukemia (AML) and acute lymphoid leukemia (ALL) (10). Fbxl2 activity results in cell cycle arrest in $\mathrm{G}_{0}$ and subsequent apoptosis. The anti-proliferative activity of Fbxl2 in B-cell lymphoma and leukemia suggests a role in hematologic malignancies.

\section{Fbxo7}

The F box-containing proteins in which the substrate interaction domain is neither a WD40 nor leucine-rich repeat are designated as Fbxo (other domain) proteins. Among these, genetic ablation of Fbxo7 in mice has been reported to increase pro-B cell and pro-erythroblast populations (43). Furthermore, the expression of Fbxo7 in hematopoietic progenitor cells cooperates with p53 loss to promote T-cell malignancy suggesting its oncogenic potential (44). Hence, identification and validation of additional substrates of Fbxo7 may elaborate its role in the pathogenesis of hematologic malignancies.

\section{Fbxo9}

Fbxo9 is an other domain containing $\mathrm{F}$ box protein. Its expression has been reported to be approximately fivefold elevated in multiple myeloma (MM) cells. In a study examining a cohort of $180 \mathrm{MM}$ patients, the neoplastic cells in $30 \%$ of cases showed overexpression of Fbx09 (45). Notably, the UPS has been recognized as a promising therapeutic 
target in multiple myeloma, the second most common hematologic malignancy in western countries (46-48). Indeed the proteasome inhibitor bortezomib has gained utility as first line treatment for this disease $(46,47)$. High expression level of Fbxo9 correlates with higher progression-free survival and better prognosis in MM patients treated with bortezomib (45). This suggests that Fbxo9 may be a useful marker to predict clinical response to proteasomal inhibition. Fbxo9 regulates mTOR signaling toward cell survival and growth via mTORC1 specific degradation of Tel2 and Tti1 in multiple myeloma. Identification of Fbxo9 target substrates are limited and required further exploration.

\section{Fbxol0}

The Fbxo10 is other domain containing $\mathrm{F}$ box protein. The Fbxo10 mRNA levels are decreased in germinal center (GC) derived (approximately 33\%) and activated B cell (approximately 46\%) type of diffuse large B-cell lymphomas (DLBCL) patient samples as compared to naive B cells (11). Moreover, frameshift and missense mutations have been observed in the Fbxo10 gene in DLBCL (11). These mutations significantly compromise the ubiquitin ligase function of Fbxo10. Specifically, mutation at F box domain (R44H) abrogates the capacity of Fbxo10 to interact with Skp1 adapter protein to form a functional SCF E3 ligase complex. Further mutations in the CASH domain of Fbxo10 (V762L and $\mathrm{R} 825 \mathrm{~W})$, which is responsible for substrate interaction, partially compromise Fbxo10 function (11). Fbxo10 mutants were less toxic than wildtype presumably by impairing its tumor suppressor function. Fbxo10 mutations identified in DLBCLs are heterozygous and hypomorphic in nature, indicating that Fbxo10 functions as a haploinsufficient tumor suppressor. However, absence of Fbxo10 homozygous mutations suggests that its activity may be critical for development of lymphoma. DLBCL are the most common form of B-cell lymphoma accounting for approximately 30-40\% of newly diagnosed non-Hodgkin's lymphoma (49). To fully understand the critical balance between the level and activity of Fbxo10 required for normal physiology but not for lymphoma development, it will be important to understand how the level of this protein is regulated and further what are the other substrates and cellular pathways that are controlled by Fbxo10-mediated proteasomal degradation.

\section{Fbxoll}

Fbxo11, another family member of Fbxo group, is targeted for deletion and mutation in multiple DLBCL cell lines and primary samples (50). These deletions were largely monoallelic, suggesting a haplo-insufficient tumor suppressor function for Fbxo11. The mutations identified, altered the subcellular localization of protein. Most of the mutations have been shown to target the substrate binding $\mathrm{CASH}$ domain rendering the Fbxo11 functionally compromised. Specifically, in OCILY1 (germinal center B-like DLBCLderived) cells, Fbxo11 gene locus sequencing revealed a point mutation in the CASH domain. Furthermore, analysis of approximately 100 primary DLBCL samples revealed six sequence variants that were shown to be somatic by analysis of paired normal DNA. Five of the six identified mutations were in the CASH domain and one of these five mutations was a frameshift mutation generating a functionally defective Fbxo11 protein. Most of the Fbxo11 alterations were hemizygous deletions $(14.8 \%, \mathrm{n}=27)$ and inactivating missense or frame shift mutations $(14.3 \%, \mathrm{n}=7)$ in DLBCL cell lines, and mutations $(4 \%, n=100)$ in primary DLBCL samples (12). Moreover, gene copy analysis by two independent studies also report Fbxo11 deletions $(8.7 \%, \mathrm{n}=69)$ in human DLBCLs samples analyzed (50). Since Fbxo11 mutations are often identified in substrate recruitment domain, it is conceivable that Fbxo11 deletions or mutations may contribute to DLBCL pathogenesis by stabilizing substrate oncoproteins critical for disease progression. Identification of novel Fbxo11 substrates in germinal center-derived B cells may provide significant insight onto the role of Fbxo11 in B-cell malignancy.

\section{$\mathrm{c}-\mathrm{CBL}$}

Originally identified as cellular homolog of murine viral oncogene ( $\mathrm{v}-\mathrm{Cbl})$, the casitas B-lineage lymphoma (cbl) family of E3 ubiquitin ligases specifically target receptor tyrosine kinase-mediated signaling pathways as well as Akt-PI3K and Ras-Raf-MAPK pathways (51, 52). The $\mathrm{N}$-terminal regions of $\mathrm{Cbl}$ family proteins are highly conserved and include the tyrosine kinase binding (TKB), RING finger $(\mathrm{RF})$, and short linker region between these two domains. The RING finger domain and the linker region together mediate recruitment of E2 ubiquitin-conjugating enzymes and thus are essential for the E3 ligase activity of Cbl proteins (53). Although CBL mutations have been reported in a variety of myeloid neoplasms, the mutations are most frequently observed in myelodysplastic syndromes: myeloproliferative neoplasm (MDS/MPN), including chronic myelomonocytic leukemia (CMML) (approximately 15\%), juvenile myelomonocytic leukemia (JMML) (approximately 
$17 \%$ ), and atypical chronic myeloid leukemia (approximately 5\%) (54-62). Further somatic c-CBL mutations have also been reported in acute lymphoblastic leukemia (ALL) (63). Most c-CBL mutations in MPNs such as AML are identified within the linker/RING finger domains, and are predicted to abrogate the interaction of $\mathrm{C}-\mathrm{CBL}$ with $\mathrm{E} 2$ conjugating enzymes, and thus impair the E3 ligase activity of the molecule (62). The tumor-derived mutations in linker/RING domain have shown severely compromised E3 ligase activity when expressed in fibroblast cells $(60,62)$.

\section{Smurf2}

Smurf2 (Smad ubiquitination regulatory factor-2) is a HECT domain type E3 ubiquitin ligase that is involved in the degradation of critical substrates involved in establishment and functioning of the germinal center reaction. From the published microarray data set (GSKE2350) for human primary B-cell lymphoma samples and normal B cells it was observed that human primary B-cell lymphomas (DLBCL, BL, and FL) express lower levels of Smurf2 as compared to normal B cells (18). Smurf2-deficient mice exhibit increased proliferation of splenic B cells and develop GC or post GC-derived B-cell lymphomas suggesting a tumor suppressor function for Smurf2 (18). Smurf2 is also an important regulator of senescence and in the absence of apoptosis; senescence becomes prominent tumor suppressor mechanism to overcome oncogenic activities within cells. However, Smurf2deficient cells bypass the senescence program and undergo prolonged cell proliferation in splenic B cells providing a favorable background for evolution to malignant lymphoma (64). Genetic analysis has not observed a deletion at Smurf2 locus in human DLBCL, suggesting a possible role for epigenetic or post-transcriptional regulation of Smurf2 deficiency in human lymphomagenesis. DLBCL and BL patients having low expression levels of Smurf2 exhibit poorer prognosis than patients having higher Smurf2 levels. Interestingly, the level of Smurf2 does not correlate with follicular lymphoma patient survival suggesting that Smurf2 expression can specifically be a valuable prognostic marker for DLBCL and possibly BL patients (18).

\section{UBR5}

UBR5 is a HECT domain type E3 ubiquitin ligase that plays a critical role in cell cycle progression and DNA damage response pathways $(65,66)$. UBR5 has been found to be recurrently mutated in mantle cell lymphoma (MCL) characterized primarily by the recurrent $t(11,14)(q 13 ; q 32)$ aberration resulting in constitutive overexpression of cyclin D1 (15). Majority of UBR5 mutations (61\%) result in frame shifts in or around exon 58 and are predicted to generate functionally defective UBR5 protein. The consequences of defective UBR5 and its ubiquitination substrates responsible for progression of MCL are yet to be determined and offer an interesting avenue for identification of novel substrates that can be exploited for therapeutic targeting.

\section{Deregulated E3 ubiquitin ligase substrates that are implicated in hematologic malignancies}

There are many key cellular players involved in cell cycle regulation, transcriptional control, or epigenetic modulation of gene expression that participate in the pathogenesis of hematologic malignancies. Often, the abundance and activity of these regulators are controlled at the post-translational level by the UPS and aberrant turnover of these proteins due to defect in degradation signal or mutation/deletion/aberrant expression of degradation machinery may facilitate progression to outright malignancy through inappropriate turnover of substrates critical for proper hematopoiesis. The following section highlights the selected critical regulators of hematopoiesis which are regulated at post-translational level by the UPS

\section{$\mathrm{EZH} 2$}

EZH2 (enhancer of zeste homolog 2), a SET domain-containing histone methyltransferase, is a critical enzymatic subunit of the polycomb repressive complex 2 (PRC2) which trimethylates histone $\mathrm{H} 3$ (H3K27) to mediate gene repression (67). The activity of EZH2 largely depends upon assembly of core complex involving other PRC2 components, EED (embryonic ectoderm development) and SUZ12 (suppressor of zeste 12) (68). Appropriate level and activity of EZH2 is critical for normal development because EZH2 deletion is lethal in early embryonic development and EZH2 knockout embryos fail to implant and undergo gastrulation (69). In lineage-specific stem cells of diverse origin, EZH2 and cooperating proteins regulate the proper coordination of differentiation and proliferation (70-72). EZH2 is expressed at high levels in human germinal center B cells, and its expression levels fluctuate according to maturation state of B cells. EZH2 expression is high in germinal center $\mathrm{B}$ cells to maintain the germinal center phenotype long enough to mediate multiple rounds of division and somatic hypermutation for antibody affinity maturation and decline once B cells exit the germinal center $(73,74)$. 
Somatic mutations, overexpression, and hyperactivation of EZH2 have been reported in the pathogenesis of several malignancies (71). Genome-wide sequencing studies recently identified heterozygous somatic and recurrent gain-of-function mutations targeting $\mathrm{EZH} 2^{\mathrm{Y} 641}$ occurring most frequently in germinal center derived follicular and aggressive diffuse large B-cell lymphoma. This mutation is associated with H3K27me3 hyper-activation promoting lymphomagenesis (73-76). These mutations have been reported to alter the enzymatic activity of EZH2 (with preference for trimethylation of $\mathrm{H} 3 \mathrm{~K} 27$ ) as well as its stability, resulting in a protein with prolonged half-life. $\mathrm{SCF}^{\beta \mathrm{TrCP}}$ E3 ubiquitin ligase recognizes Y641 phosphorylated EZH2 for polyubiquitination and degradation by $26 \mathrm{~S}$ proteasome system (77). The mutations at Y641 compromise the phosphorylation of EZH2 by Jak2 tyrosine kinase and ensuing recognition by $\mathrm{SCF}^{\beta \operatorname{TrCP}}$ E3 ubiquitin ligase rendering long-lived protein with attendant increase in $\mathrm{H} 3 \mathrm{~K} 27$ trimethylation activity. Usually $\beta \operatorname{TrCP}$ recognizes a conserved phospho-degron $\operatorname{DpSG}(\mathrm{X})_{2-5} \mathrm{pS}$ through its critical residues $\mathrm{R} 474$ residing in its 7 th $\mathrm{WD}$ repeat region (78). It has been demonstrated that the $\mathrm{SCF}^{\beta \operatorname{TrCP}} \mathrm{R} 474 \mathrm{~A}$ mutant is unable to recognize EZH2 adding another layer of complexity to post translational regulation of EZH2 (77). Therefore, further studies on the detailed molecular mechanism of EZH2 degradation by $\beta \mathrm{TrCP}$ and involvement of secondary signaling including the role of Jak2 kinase in the context of B-cell lymphoma pathogenesis at germinal center microenvironment may provide potential new therapeutic opportunities against EZH2 driven lymphomagenesis.

\section{BCL6}

BCL6 is a transcriptional repressor required to maintain germinal center reaction very much like EZH2 and its deregulation has been implicated in the pathogenesis of human B-cell lymphoma (79). BCL6 controls the germinal center program through transcriptional repression of a variety of genes to prevent premature activation and differentiation of B cell toward memory and plasma cells (80-88). Chromosomal translocations involving BCL6 (approximately 40\%) and overexpression of BCL6 through promoter hypermutation (approximately 15\%) have been identified in aggressive diffuse large B cell lymphomas (DLBCL), the most common lymphoma in adulthood (12, 89-92). Apart from promoter hypermutation or chromosomal translocation, proteasomal degradation of BCL6 is another mechanism of its regulation within germinal center (12). BCL6 is targeted for ubiquitination and degradation by $\mathrm{SCF}^{\text {Fbxo11 }}$ (12). SCF ${ }^{\text {Fbxo11 }}$ mediated degradation of BCL6 regulates its optimal required levels/activity in germinal center B cell and during germinal center exit for the generation of memory B cell and plasma cells. Fbxo11 silencing in a DLBCL cell line promotes tumorigenesis in immunodeficient mice and its reconstitution suppresses tumor growth. Frequent deletion and mutations of Fbxo11 have been identified in multiple DLBCL cell lines and primary DLBCL patient samples, and loss of Fbxo1 1 has been observed to promote stability of BCL6 protein. Fbxo11 mutants displayed an impaired ability to trigger BCL6 degradation and thus potentially contributing to lymphomagenesis through BCL6 stabilization. However, the secondary signaling pathways controlling Fbxo11 mediated BCL6 degradation and maturation stages of GC when BCL6 levels are controlled by degradation machinery are yet to be delineated.

\section{Notch signaling components}

Notch signaling plays a critical role in lineage commitment during lymphocyte development and further in oncogenic transformation (93). Hyperactivation of Notch signaling has been implicated in several hematologic malignancies including T-cell acute lymphoblastic leukemia (T-ALL), B-chronic lymphocytic leukemia, and splenic marginal zone lymphoma (94-97). Further, adding another layer of complexity to lineage specific functions, Notch signaling evokes tumor suppressor activity in myeloid malignancies (98). It therefore appears that oncogenic or tumor suppressor activities of Notch signaling pathways are highly context dependent. Notch signaling is significantly regulated by the UPS, and deregulation of Notch1 signaling due to activating mutations in Notch 1 receptors that impair its recognition and degradation by $\mathrm{SCF}^{\mathrm{Fbxw} 7} \mathrm{E} 3$ ligase has been reported to promotes lymphomagenesis $(16,19)$. Notch1-Fbw7 axis is very well characterized, however the C-terminal PEST domain of Notch is highly conserved among different Notch proteins. Two independent studies identified Notch2 mutations in splenic marginal zone lymphoma (SMZL) patients using whole genome sequencing $(94,95)$. The mutational frequency ranged from $21 \%$ to $25 \%$ of cases, targeting Notch2 as the most mutated gene in both of these studies. Most of the identified mutations targeted the conserved $\mathrm{C}$ terminal PEST region predicted to be docking sites for E3 ligase(s) involved in the proteasomal turnover of the Notch2 protein $(94,95)$. It is tempting to speculate that 
frame shift and deletion mutations targeting PEST domain may increase the stability of mutant Notch2 protein with attendant hyperactivity directed toward progression of SMZL. Further studies are required to establish the mechanism of hyperactivation of Notch signaling induced by the Notch2 mutations and identification of possible additional E3 ligase machinery that might participate in Notch2 posttranslational regulation.

\section{NF $\kappa$ B signaling components}

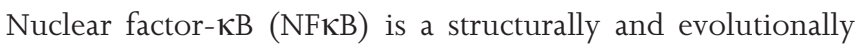
conserved family of transcription factors that are critical for the development of $\mathrm{T}$ and B lymphocytes (99). Activation and regulation of $\mathrm{NF} \kappa \mathrm{B}$ transcription factors is highly dependent on the developmental stage and the initiating signal. NFKB family is consists of five structurally related activators (RelA or p65, RelB, c-Rel, p50, and p52) and five inhibitory proteins [p100, p105, and Inhibitor of $\kappa \mathrm{B}(\mathrm{I} \kappa \mathrm{B} \alpha$, $\mathrm{I} \kappa \mathrm{B} \beta$, and $\mathrm{I} \kappa \mathrm{B} \varepsilon)](100)$. The activators are synthesized as mature products and harbor C-terminal transactivation domains. The p50 and p52 activators are products of proteolytic processing of long precursors p105 and p100, respectively. The NFKB activators share a 300 amino acid Rel homology domain (RHD) that regulates the binding, dimerization and nuclear localization of active NFKB transcription factor. The five inhibitors possess ankyrin repeat domains (ARDs) that associate with RHDs of NFKB members to exert inhibitory activity, primarily by sequestering them in the cytoplasm. NFKB signaling is activated through two principal pathways; namely the classical and alternate pathway. Although both pathways show similarity in proteasomal degradation of inhibitory components of pathway triggering activation of signaling, the factors such as nature of stimuli, upstream kinase and inhibitor of $\kappa \mathrm{B}$ kinase (IKK) complex composition, resulting heterodimer of $\mathrm{NF \kappa B}$ transcription factor and identity of the regulated target genes dictates the pathway type. The classical pathway is triggered by proinflammatory cytokines [tumor necrosis factor $\alpha$ (TNF $\alpha$ ), interleukin IL-1 $\beta$, or ligand of $\mathrm{T}$-cell or the B-cell receptor]

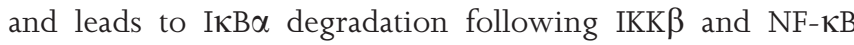
essential modulator (NEMO)/IKK $\gamma$ driven phosphorylation, releasing RelA/p50 heterodimer and are associated with innate immunity. On the other hand, the alternative pathway is stimulated by members of TNF cytokine family (lymphotoxin- $\beta$, BAFF, and CD40) and relies on the IKK $\alpha$ mediated p100 phosphorylation regulated by NIK dependent and NEMO/IKK $\gamma$ independent pathways, releasing hetero-dimeric transcription factor RelB either associated with p50 or p52 and these pathways are mainly involved in adaptive immunity (101). Aberrant activation of NFKB signaling is directly associated with several hematological malignancies. In this regard, multiple myelomas (MM) exhibits constitutive activation of $\mathrm{NF} \kappa \mathrm{B}$ signaling and often carry a variety of $\mathrm{NF} \kappa \mathrm{B}$ pathway mutations, most of which are affecting the pathway upstream of I $\mathrm{B}$ degradation. Bortezomib, an inhibitor of the 26S proteasome, is used for the treatment of multiple myeloma which partly prevents the degradation of $\mathrm{NF \kappa B}$ inhibitory proteins and consequently ablates the oncogenic signal triggered by NFKB activation (47). Success of proteasome inhibitor treatment reinforced targeted inhibition of other ubiquitin proteasome components for therapeutic intervention. To this end, the neddylation inhibitor MLN4924, which blocks the function of all cullin-RING ubiquitin ligases (CRLs) entered phase I clinical trial for multiple myeloma and showed effective blockade of NFKB signaling in multiple myeloma as well as activated B-cell type diffuse large B-cell lymphoma (102105). The E3 ligase activity of CRLs largely depends upon NEDD8, a 9 kDa ubiquitin like small molecule, modification on cullin scaffold protein. Neddylation is mediated through enzymatic cascades much akin to the ubiquitin system and is initiated by NEDD8 activating enzyme (NAE). Therefore, inhibition of NAE abrogates NEDD8 modification and consequently compromises the CRL E3 ligase function (106). Two SCF type E3 ligases, Fbxw1 ( $\beta \operatorname{TrCP}$ ) and Fbxw7 $\alpha$, have been implicated in the regulation of the $\mathrm{NF \kappa B}$ pathway $(99,104,107)$. $\beta \operatorname{TrCP}$ polyubiquitinates I $\mathrm{I} B \alpha$ as well as p105 for proteasomal degradation while triggering the proteolytic processing of p100 to generate p52, the active component of NFאB transcription factor, which directs activation of canonical as well as non-canonical NFKB signaling (108-110). Fbxw7 $\alpha$ is responsible for ubiquitination and degradation of nuclear p100 and thus favors noncanonical pathway activation (104). How these two F boxcontaining proteins are coordinated for activation of a particular NFאB pathway and the context at which the specific E3 ligase activity prevails for canonical or non-canonical NFKB pathway activation are not yet clearly understood and need further exploration.

\section{Myc}

The Myc family of transcription factors plays pivotal roles in several critical cellular processes including growth, apoptosis, and proliferation (111). Overexpression and chromosomal 
translocation mediated hyperactivation of c-Myc oncoprotein has been observed in large number of hematologic malignancies including Burkitt lymphoma. The c-Myc oncoprotein also undergoes another layer of regulation through $\mathrm{SCF}^{\mathrm{Fbxw}}$ mediated proteasomal degradation. Several mutations identified in the coding region of c-Myc center around Thr 58 which undergoes phosphorylation by GSK3 $\beta$ and facilitates recognition and polyubiquitination of c-Myc by Fbxw7 for degradation (112). Proteasome-mediated degradation of cMyc is significantly impaired in Burkitt lymphoma harboring Thr58 or other mutations critical for Fbxw7-mediated recognition of the transcription factor $(112,113)$. The counteracting activity of C-Myc as well as v-Jun and Notch-1 ubiquitination (substrates of Fbxw7 $\alpha$ ) has been shown to be mediated by the USP28 DUB in colorectal cancer (114). However, its role in c-Myc driven progression of hematologic malignancy is not explored and offers a potential avenue for further studies.

\section{Role of deubiquitinases in hematologic malignancies}

The activities of E3 ubiquitin ligases are counteracted by DUBs, which remove ubiquitin protein from the substrates and thereby regulate the level and activity of the protein substrates. Therefore, similar to E3 ubiquitin ligases, dysregulation of DUBs also contributes to the pathogenesis of hematologic malignancies. However, unlike E3 ligases, the DUBs and their roles in the progression of hematologic malignancy have not been explored extensively.

On the basis of their domain structure, DUBs are classified in to five families: the ubiquitin carboxy-terminal hydrolases (UCHs), the ubiquitin-specific proteases (USPs), the ovarian tumor-related proteases (OTUs), the MachadoJoseph disease protein domain proteases (MJDs), and the JAB1/PAB1/MPN-domain containing metallo-enzyme (JAMMs). The USPs constitutes the largest family of DUBs with 53 USP genes that are identified in the human genome.

\section{USP9X}

USP9X is overexpressed in several B-cell malignancies including follicular lymphoma, diffuse large B-cell lymphoma, and multiple myeloma (115). The overexpression of USP9X has been significantly associated with poor prognosis for patients with multiple myeloma (115). Patients overexpressing USP9X had a 5.5-fold greater risk of death (115). USP9X promotes cell survival, at least in part by deubiquitination of MCL1, a pro-survival BCL2 family member. USP9X stabilizes MCL1 protein by removing its degradative Lys 48-linked polyubiquitin chain. Increased levels of MCL1 are associated with poor outcome in multiple myeloma (116), relapsing acute myeloid leukemia and acute lymphocytic leukemia (117). Hence, targeting USP9X through pharmacologic inhibition might be therapeutically advantageous against B-cell malignancies associated with increased expression of USP9X.

USP9X also plays a pivotal role in T-cell proliferation, cytokine production, and Th (T-helper) cell differentiation by regulating TCR-induced NFKB signaling (118). Since USP9X has different target substrates depending upon the cell type, further studies are needed to gain more insight into the mechanism of USP9X function and regulation in B and T-cell signaling. Development of inhibitors of USP9X is underway and might offer important therapeutic benefit in hematologic malignancies associated with aberrant activity of USP9X (119).

\section{CYLD}

CYLD, a member of the USP class of DUBs, was originally identified as a tumor suppressor in familial cylindromatosis, a disease characterized by development of multiple skin tumors mostly on the scalp (120). Tumors were characterized by loss of heterozygosity, and the majority of the mutations were clustered at the catalytic domain of second copy of the gene rendering the protein non-functional $(121,122)$. Furthermore, CYLD is located on 16q12-13, a region recurrently deleted in cHL and its expression are decreased in human T-ALL $(123,124)$. CYLD is a negative regulator of NFKB signaling and its loss enhances NFKB signaling following TNF stimulation (125-127). CYLD also exhibits NFKB independent roles that may be associated with neoplastic progression including regulation of mitotic entry and cytokinesis $(128,129)$ and enhancement of cell migration $(130,131)$. As a negative regulator of NFKB signaling and having independent oncogenic function, it is anticipated that CYLD might play yet undiscovered roles in the pathogenesis of hematologic malignancies.

\section{A20}

A20, also known as TNF $\alpha$ induced protein-3 (TNFAIP3), is an N-terminal OTU domain-containing ubiquitin editing enzyme with dual function as E3 ubiquitin ligase and DUB and primarily attenuates NFKB-mediated proinflammatory signaling (132). It contains seven zinc finger $(\mathrm{ZnF})$ domains in its $\mathrm{C}$-terminus, including $\mathrm{ZnF} 4$ that functions as an $\mathrm{E} 3$ 
ligase, and an OTU domain for deubiquitination embedded in its $\mathrm{N}$ terminus $(132,133)$. A20 overexpression inhibits $\mathrm{NF \kappa B}$ activation in response to different stimuli. It is known to function as tumor suppressor in several types of hematologic malignancy and is inactivated by deletions, promoter hypermethylation, frame shift and nonsense mutations that result in impaired protein function (133-139). Biallelic mutations in the coding region of A20 have been identified in approximately $30 \%$ of B-cell lymphomas, including diffuse large B-cell lymphoma, mantle cell lymphoma, marginal zone lymphoma of mucosa-associated lymphoid tissue, and Hodgkin's lymphoma (133-139). A20 inactivation by any mechanism contributes to lymphoma progression by rendering unchecked and abnormally prolonged NFKB activity resulting in decreased apoptosis and increased cell survival (133-139). A20 inactivation is also observed in T-cell malignancies including T-ALL and Sezary syndrome (140, 141). High resolution array comparative genomic hybridization (aCGH) has shown mono and biallelic deletion of A20 in significant proportion of SS samples and its restoration retarded cell cycle progression, while knockdown of A20 in normal $\mathrm{T}$ cells promoted proliferation suggesting a tumor suppressor role of A20 in T-cell malignancy (141). Apart from its well-characterized role in inhibiting NFкB signaling, A20 also regulates other cellular signaling circuits including the Wnt pathway, the autophagic response and the interferon regulatory factor (IRF) pathway (142-146). Considering the genetic aberrations of A20 associated with several hematologic malignancies and its role in the regulation of diverse cellular signaling including inhibition of NFKB signaling, apoptosis, and inflammation, future studies involving the regulatory mechanisms of A20 and its ubiquitin modulating activity on novel substrates might provide opportunities for therapeutic interventions in A20 dysregulated hematologic neoplasms.

\section{Therapeutic opportunities and current clinical trials targeting UPS in hematologic malignancies}

The proteasome subunits are overexpressed in hematologic malignancies. Notably, neoplastic cells of hematopoietic origin are significantly more sensitive to proteasomal inhibition by lactacystin as compared to their normal counterparts indicating the critical role UPS plays in hematopoietic neoplasia (147-150). Inhibition of the proteasome was reported to result in largely selective apoptosis in patientderived lymphoma and leukemia cells, while considerably sparing the untransformed cells. Hence, several proteasome inhibitors with different mechanisms of action are currently in several stages of clinical trials for different subsets of lymphoma/leukemia.

\section{Proteasome inhibitors currently in clinical trial}

\section{Bortezomib}

A proteasome inhibitor that has had huge impact on treatment of hematologic malignancy is bortezomib (Velcade ${ }^{\mathrm{TM}}$, Millennium: the Takeda Oncology Company, Cambridge, Massachusetts) $(46,47,151)$. Bortezomib is the first FDA approved proteasome inhibitor now used as a frontline treatment for newly diagnosed multiple myeloma (MM), relapsed/refractory $\mathrm{MM}$, and mantle cell lymphoma. Less efficacious but nevertheless encouraging responses have also been observed in DLBCL and follicular lymphoma patients (152). The major cellular machinery for proteolytic processing is the 26S proteasome, an ATP-dependent complex comprised of a 20S catalytic core subunit and 19S regulatory subunits (153). The 20S proteasome subunit is responsible for the degradation of ubiquitinated substrates. Bortezomib inhibits this machinery by reversibly binding to active site of $20 \mathrm{~S}$ proteasome. Bortezomib has shown notable success in the treatment of $\mathrm{MM}$ and MCL, but it is not a perfect drug. It is an unstable compound that retains activity only within 4-8 h of reconstitution, and its therapeutic window is narrow (154). Above its therapeutic dosage $\left(1.3 \mathrm{mg} / \mathrm{m}^{2}\right.$ body surface) and even at $1.5 \mathrm{mg} / \mathrm{m}^{2}$, it produces toxicity that includes myelosuppression which leads to anemia, neutropenia, and thrombocytopenia, and neuropathy, which occurs in more than $30 \%$ patients (154). Furthermore, resistance to bortezomib treatment is an emerging issue emphasizing the requirement for the development of second generation inhibitors. To this end, several promising novel proteasomal inhibitors have been developed and characterized in vitro, in vivo, and in clinical settings. Compared to bortezomib, these agents are highly selective and irreversible proteasomal inhibitors.

\section{Carfilzomib}

Carfilzomib, or PR171, is a proteasome inhibitor consisting of a tetrapeptide epoxyketone. Carbilzomib irreversibly binds to the $\beta 5$ subunit of the 20 S proteasome, resulting in inhibition of the chymotrypsin-like activity. In July 2012, the FDA approved carfilzomib for the treatment of MM patients who have received at least two prior therapies including bortezomib and an immunomodulatory agent (IMID) and have shown disease progression within 60 days of completion of the last therapy. Preclinical studies demon-

(C) 2014 John Wiley \& Sons A/S. Published by John Wiley \& Sons Ltd Immunological Reviews 263/2015 
strated that carfilzomib was active against bortezomib-resistant multiple myeloma cell lines (155).

\section{Marizomib}

Marizomib (NPI-0052 or salinosporamide A) is a $\beta$-lactone$\gamma$ lactam structure containing natural proteasomal inhibitor extracted from actinomycetes Salinispora tropica (156). Unlike bortezomib, marizomib irreversibly binds to the proteasome and inhibits the three major enzymatic activities (chymotrypsin-, trypsin-, and caspase-like). As compared to bortezomib, marizomib showed improved therapeutic efficacy in hematologic malignancy including activity on bortezomib-resistant MM. In addition to MM, the therapeutic efficacy of marizomib was also examined in MCL, Waldenstrom's macroglobulinemia (WM), chronic and acute lymphocytic leukemia. Interestingly, marizomib in combination with various histone deacetylase (HDAC) inhibitors induced greater levels of cell death than the combinations of HDAC inhibitors and bortezomib $(157,158)$.

\section{Orally active proteasome inhibitors}

Technical challenges and cost effectiveness issues associated with administration of bortezomib compelled researchers to search for orally administered proteasomal linhibitors that can be utilized or therapeutic approaches.

\section{Ixazomib}

Ixazomib (MLN 9708) is the first reversible oral proteasome inhibitor to enter clinical investigation (159). Ixazomib is administered as a stable citrate ester (ixazomib citrate) that under physiological conditions rapidly hydrolyses to ixazomib. It preferentially inhibits the chymotrypsin- like site of the 20S proteasome. However, at higher concentrations, it also inhibits the caspases-like and trypsin-like proteolytic sites. Ixazomib inhibits growth and stimulates apoptosis in MM cells that are resistant to conventional and bortezomib therapies, while normal cells are relatively spared from toxicity.

\section{Oprozomib}

Oprozomib (ONX0912), is an orally bioavailable epoxyketone-based proteasome inhibitor and like carfilzomib, inhibits the chymotrypsin-like activity of the proteasome and induces cell death in myeloma cell lines and primary cells from MM patients without appreciable cytotoxicity in normal hematopoietic cells (160). Oprozomib treatment is effective in patients who relapsed after treatment with bortezomib, dexamethasone, or lenalidomide.

\section{Delanzomib}

Delanzomib (CEP-18770) is a novel orally active inhibitor of the chymotrypsin like activity of the proteasome. This drug has advanced to phase 1 clinical trial for non-Hodgkin's lymphoma (161). Like bortezomib, delanzomib is a reversible proteasomal inhibitor. Initial studies using delanzomib have shown a greater and more sustained dose-dependent inhibition in primary MM plasma cells in vitro (162).

\section{Conclusions and future perspective}

The controlled degradation of cell regulatory substrates involved in cell cycle progression, cell cycle checkpoint, response to genotoxic stress, signaling pathways, and transcriptional control of gene expression is prerequisite for normal cellular homeostasis. In this context, the UPS plays a vital role through precise temporal and context specific degradation of regulatory proteins. Deregulation of the UPS in hematopoietic cells results in complex outcomes contributing to the pathogenesis of hematopoietic malignancies. However, inhibition of the proteasome system is expected to accumulate the levels of hundreds of proteins regardless of their role in cellular physiology and consequently kill normal cells along with cancer cells. The activity of the ubiquitination cascade comprising the E1, E2, and E3 enzymes is counteracted by the activity of the DUBs. Among the three enzymes in the cascade, the E3 ubiquitin ligases control a remarkable diversity of substrates with utmost specificity. Hence, it is not surprising that these E3 ligases are deregulated by multiple mechanisms ensuing aberrant cellular response through their substrate abundance leading to the development and progression of hematologic malignancies. Although E3 ligases have been implicated in regulation of diverse array of substrates, the understanding of the subcellular location, context, and co-factors that dictate the degradation of these substrates at particular physiologic or pathologic states of cells is far from complete. A goal of studying E3 ligase-mediated control of substrates regulating critical cellular processes is to develop a therapeutic intervention against aberrant activity of these ligases in cancer contexts. A notable advance in this arena is the FDA approval of bortezomib (a general proteasome inhibitor) and use of neddylation inhibitor (MLN4924) in clinical management of various cancers. However, the strategy of inhibition of the proteasomal apparatus carries unwanted complications and lined to harmful effects on normal cells. Thus, there is an exquisite need for effective regulators of E3 ligases that target specific cellular substrates in efficacious formulations and 
with minimal side effects. Such agents may plausibly be alternatives or adjunctive to other currently existing effective cancer therapeutics. Also noteworthy are the counteracting activities of DUBs that balance the turnover of critical cellular regulators mediated by ubiquitination-driven proteasomal degradation. Hence, aberrant expression and activity of deubiqutinases also contribute to blood cancer. For example, USP9X is overexpressed in leukemia and MM cells. To this end, a small molecule inhibitor WP110 has been identified as a partly selective DUB inhibitor that directly inhibit the activity of USP9x, USP5, USP14, and UCH37 (163, 164). These DUBs are known to regulate survival protein's stability and $26 \mathrm{~S}$ proteasome function. However, knowledge on role of different DUBs in hematologic neoplasms and their target substrates as well as their mechanisms of action is quite limited and requires further exploration.

The preponderance of evidence implicates aberrant proteasomal degradation machinery as strongly contributing or driving the evolution of several hematologic malignancies. Furthermore, the extent to which post-translational modifications (phosphorylation, methylation, acetylation, or ubiquitylation) influence the turnover of substrates through the proteasomal machinery remains to be determined. Presently, several laboratories are utilizing state-of-the-art tools including next generation sequencing and advanced proteomic approaches to identify structural alterations that subvert normal proteolytic degradation of critical substrates involved in hematopoietic homeostasis. Further, in vivo experimental models are being developed to provide a more sophisticated understanding of the deregulated UPS pathway in hematologic neoplasia. Continued efforts in this arena worldwide are anticipated to reveal insights that will facilitate better understanding of contribution of the UPS to the development of hematologic malignancies and elucidate novel avenues for the development of novel treatments for hematopoietic neoplasms.

\section{References}

1. Hershko A. Some lessons from my work on the biochemistry of the ubiquitin system. J Biol Chem 2009;284:10291-10295.

2. Hershko A. The ubiquitin system for protein degradation and some of its roles in the control of the cell-division cycle (Nobel lecture). Angew Chem Int Ed Engl 2005;44:5932-5943.

3. Silverman JS, Skaar JR, Pagano M. SCF ubiquitin ligases in the maintenance of genome stability. Trends Biochem Sci 2012;37:66-73.

4. Nakayama KI, Nakayama K. Ubiquitin ligases: cell-cycle control and cancer. Nat Rev Cancer 2006;6:369-381.

5. Lim MS, Elenitoba-Johnson KS. Ubiquitin ligases in malignant lymphoma. Leuk Lymphoma 2004;45:1329-1339.

6. Hershko A, Ciechanover A. The ubiquitin system. Annu Rev Biochem 1998;67:425-479.

7. Frescas D, Pagano M. Deregulated proteolysis by the F-box proteins SKP2 and beta-TrCP: tipping the scales of cancer. Nat Rev Cancer 2008;8:438-449.

8. Glickman MH, Ciechanover A. The ubiquitin-proteasome proteolytic pathway: destruction for the sake of construction. Physiol Rev 2002;82:373-428.

9. Kitagawa K, Kotake Y, Kitagawa M. Ubiquitin-mediated control of oncogene and tumor suppressor gene products. Cancer Sci 2009; 100:1374-1381

10. Chen BB, et al. F-box protein FBXL2 targets cyclin D2 for ubiquitination and degradation to inhibit leukemic cell proliferation. Blood 2012;119:3132-3141.

11. Chiorazzi M, et al. Related F-box proteins control cell death in Caenorhabditis elegans and human lymphoma. Proc Natl Acad Sci USA 2013;110:3943-3948.
12. Duan S, et al. FBXO11 targets BCL6 for degradation and is inactivated in diffuse large B-cell lymphomas. Nature 2012;481:90-93.

13. Kao HW, et al. A high occurrence of acquisition and/or expansion of C-CBL mutant clones in the progression of high-risk myelodysplastic syndrome to acute myeloid leukemia. Neoplasia 2011;13:1035-1042

14. Latres E, et al. Role of the F-box protein Skp2 in lymphomagenesis. Proc Natl Acad Sci USA 2001;98:2515-2520.

15. Meissner B, et al. The E3 ubiquitin ligase UBR5 is recurrently mutated in mantle cell lymphoma. Blood 2013;121:3161-3164.

16. O’Neil J, et al. FBW7 mutations in leukemic cells mediate NOTCH pathway activation and resistance to gamma-secretase inhibitors. J Exp Med 2007;204:1813-1824.

17. Onoyama I, et al. Conditional inactivation of Fbxw7 impairs cell-cycle exit during $\mathrm{T}$ cell differentiation and results in lymphomatogenesis. J Exp Med 2007;204:2875-2888.

18. Ramkumar C, Cui H, Kong Y, Jones SN, Gerstein RM, Zhang H. Smurf2 suppresses B-cell proliferation and lymphomagenesis by mediating ubiquitination and degradation of YY1. Nat Commun 2013;4:2598

19. Thompson BJ, et al. The SCFFBW7 ubiquitin ligase complex as a tumor suppressor in $\mathrm{T}$ cell leukemia. J Exp Med 2007;204:1825-1835.

20. Bassermann F, Eichner R, Pagano M. The ubiquitin proteasome system - implications for cell cycle control and the targeted treatment of cancer. Biochim Biophys Acta 2014;1843:150162.

21. Silverman JS, Skaar JR, Pagano M. SCF ubiquitin ligases in the maintenance of genome stability. Trends Biochem Sci 2012;37:66-73.
22. Hammond-Martel I, Yu H, el Affar B. Roles of ubiquitin signaling in transcription regulation. Cell Signal 2012;24:410-421.

23. Vucic D, Dixit VM, Wertz IE. Ubiquitylation in apoptosis: a post-translational modification at the edge of life and death. Nat Rev Mol Cell Biol 2011;12:439-452.

24. Wang Z, Liu P, Inuzuka H, Wei W. Roles of F-box proteins in cancer. Nat Rev Cancer 2014; 14:233-247.

25. Cardozo T, Pagano M. The SCF ubiquitin ligase: insights into a molecular machine. Nat Rev Mol Cell Biol 2004;5:739-751.

26. Jin J, Cardozo T, Lovering RC, Elledge SJ, Pagano M, Harper JW. Systematic analysis and nomenclature of mammalian F-box proteins. Genes Dev 2004;18:2573-2580.

27. Song JH, Schnittke N, Zaat A, Walsh CS, Miller CW. FBXW7 mutation in adult T-cell and B-cell acute lymphocytic leukemias. Leuk Res 2008;32:1751-1755.

28. Crusio KM, King B, Reavie LB, Aifantis I. The ubiquitous nature of cancer: the role of the SCF (Fbw7) complex in development and transformation. Oncogene 2010;29:4865-4873.

29. Kiel MJ, et al. Integrated genomic sequencing reveals mutational landscape of T-cell prolymphocytic leukemia. Blood 2014;124:1460-1472.

30. Seki R, et al. Prognostic significance of the F-box protein Skp2 expression in diffuse large B-cell lymphoma. Am J Hematol 2003;73:230-235.

31. Lim MS, et al. Expression of Skp2, a p27(Kip1) ubiquitin ligase, in malignant lymphoma: correlation with p27(Kip1) and proliferation index. Blood 2002;100:2950-2956.

32. Starostina NG, Kipreos ET. Multiple degradation pathways regulate versatile CIP/KIP CDK inhibitors. Trends Cell Biol 2012;22:33-41. 
33. Pietenpol JA, Stewart ZA. Cell cycle checkpoint signaling: cell cycle arrest versus apoptosis. Toxicology 2002; 181-182:475-481.

34. Carrano AC, Eytan E, Hershko A, Pagano M. SKP2 is required for ubiquitin-mediated degradation of the CDK inhibitor p27. Nat Cell Biol 1999;1:193-199.

35. Sutterluty $\mathrm{H}$, et al. p45SKP2 promotes p27Kip1 degradation and induces $\mathrm{S}$ phase in quiescent cells. Nat Cell Biol 1999;1:207-214.

36. Tsvetkov LM, Yeh KH, Lee SJ, Sun H, Zhang H. p27(Kip1) ubiquitination and degradation is regulated by the $\mathrm{SCF}(\mathrm{Skp} 2)$ complex through phosphorylated Thr187 in p27. Curr Biol 1999;9:661-664.

37. Yu ZK, Gervais JL, Zhang H. Human CUL-1 associates with the SKP1/SKP2 complex and regulates p21(CIP1/WAF1) and cyclin D proteins. Proc Natl Acad Sci USA 1998;95:11324-11329.

38. Bornstein G, Bloom J, Sitry-Shevah D, Nakayama K, Pagano M, Hershko A. Role of the SCFSkp2 ubiquitin ligase in the degradation of p21Cip1 in S phase. J Biol Chem 2003;278:25752-25757.

39. Kamura T, et al. Degradation of p57Kip2 mediated by SCFSkp2-dependent ubiquitylation. Proc Natl Acad Sci USA 2003;100:10231-10236.

40. Nakayama K, et al. Skp2-mediated degradation of p27 regulates progression into mitosis. Dev Cell 2004;6:661-672.

41. Kossatz U, Dietrich N, Zender L, Buer J, Manns MP, Malek NP. Skp2-dependent degradation of p27kip1 is essential for cell cycle progression. Genes Dev 2004;18:2602-2607.

42. Nakayama KI, Nakayama K. Regulation of the cell cycle by SCF-type ubiquitin ligases. Semin Cell Dev Biol 2005; 16:323-333.

43. el Meziane K, Randle SJ, Nelson DE, Lomonosov M, Laman H. Knockdown of Fbxo7 reveals its regulatory role in proliferation and differentiation of haematopoietic precursor cells. J Cell Sci 2011;124:2175-2186.

44. Lomonosov M, el Meziane K, Ye H, Nelson DE, Randle SJ, Laman H. Expression of Fbxo7 in haematopoietic progenitor cells cooperates with p53 loss to promote lymphomagenesis. PLoS ONE 2011;6:e21165.

45. Fernandez-Saiz V, et al. SCFFbxo9 and CK2 direct the cellular response to growth factor withdrawal via Tel2/Tti1 degradation and promote survival in multiple myeloma. Nat Cell Biol 2013;15:72-81.

46. Richardson PG, et al. A phase 2 study of bortezomib in relapsed, refractory myeloma. $\mathrm{N}$ Engl J Med 2003;348:2609-2617.

47. Richardson PG, et al. Bortezomib or high-dose dexamethasone for relapsed multiple myeloma. N Engl J Med 2005;352:2487-2498.

48. Jemal A, Siegel R, Xu J, Ward E. Cancer statistics, 2010. CA Cancer J Clin 2010;60:277-300.

49. Lenz G, Staudt LM. Aggressive lymphomas. N Engl J Med 2010;362:1417-1429.

50. Duan S, et al. FBXO11 targets BCL6 for degradation and is inactivated in diffuse large B-cell lymphomas. Nature 2012;481:90-93.

51. Swaminathan G, Tsygankov AY. The Cbl family proteins: ring leaders in regulation of cell signaling. J Cell Physiol 2006;209:21-43.
52. Rao N, Dodge I, Band H. The Cbl family of ubiquitin ligases: critical negative regulators of tyrosine kinase signaling in the immune system. J Leukoc Biol 2002;71:753-763.

53. Zheng N, Wang P, Jeffrey PD, Pavletich NP. Structure of a c-Cbl-UbcH7 complex: RING domain function in ubiquitin-protein ligases. Cell 2000; 102:533-539.

54. Abbas S, Rotmans G, Lowenberg B, Valk PJ. Exon 8 splice site mutations in the gene encoding the E3-ligase CBL are associated with core binding factor acute myeloid leukemias. Haematologica 2008;93:1595-1597.

55. Dunbar AJ, et al. 250K single nucleotide polymorphism array karyotyping identifies acquired uniparental disomy and homozygous mutations, including novel missense substitutions of c-Cbl, in myeloid malignancies. Cancer Res 2008;68:10349-10357.

56. Grand FH, et al. Frequent CBL mutations associated with $11 \mathrm{q}$ acquired uniparental disomy in myeloproliferative neoplasms. Blood 2009; 113:6182-6192.

57. Niemeyer CM, et al. Germline CBL mutations cause developmental abnormalities and predispose to juvenile myelomonocytic leukemia. Nat Genet 2010;42:794-800.

58. Loh ML, et al. Mutations in CBL occur frequently in juvenile myelomonocytic leukemia. Blood 2009; 114:1859-1863.

59. Shiba N, et al. CBL mutations in juvenile myelomonocytic leukemia and pediatric myelodysplastic syndrome. Leukemia 2010;24:1090-1092.

60. Sanada M, et al. Gain-of-function of mutated C-CBL tumour suppressor in myeloid neoplasms. Nature 2009;460:904-908.

61. Caligiuri MA, et al. Novel c-CBL and CBL-b ubiquitin ligase mutations in human acute myeloid leukemia. Blood 2007;110:1022-1024.

62. Sargin B, et al. Flt3-dependent transformation by inactivating $\mathrm{c}-\mathrm{Cbl}$ mutations in AML. Blood 2007; 110:1004-1012.

63. Aarts M, et al. Forced mitotic entry of S-phase cells as a therapeutic strategy induced by inhibition of WEE1. Cancer Discov 2012;2:524539.

64. Ramkumar C, et al. Smurf2 regulates the senescence response and suppresses tumorigenesis in mice. Cancer Res 2012;72:2714-2719.

65. Gudjonsson T, et al. TRIP12 and UBR5 suppress spreading of chromatin ubiquitylation at damaged chromosomes. Cell 2012;150:697-709.

66. Smits VA. EDD induces cell cycle arrest by increasing p53 levels. Cell Cycle 2012;11:715720.

67. Yamaguchi H, Hung MC. Regulation and role of EZH2 in cancer. Cancer Res Treat 2014;46:209222.

68. Pasini D, Bracken AP, Jensen MR, Lazzerini Denchi E, Helin K. Suz12 is essential for mouse development and for EZH2 histone methyltransferase activity. EMBO J 2004;23:4061-4071.

69. O'Carroll D, Erhardt S, Pagani M, Barton SC, Surani MA, Jenuwein T. The polycomb-group gene Ezh2 is required for early mouse development. Mol Cell Biol 2001;21:4330-4336.

70. Xie H, et al. Polycomb repressive complex 2 regulates normal hematopoietic stem cell function in a developmental-stage-specific manner. Cell Stem Cell 2014;14:68-80.

71. Lund K, Adams PD, Copland M. EZH2 in normal and malignant hematopoiesis. Leukemia 2014;28:44-49.

72. Bracken AP, Dietrich N, Pasini D, Hansen KH, Helin K. Genome-wide mapping of Polycomb target genes unravels their roles in cell fate transitions. Genes Dev 2006;20:1123-1136.

73. Caganova M, et al. Germinal center dysregulation by histone methyltransferase EZH2 promotes lymphomagenesis. J Clin Invest 2013;123:50095022.

74. Beguelin W, et al. EZH2 is required for germinal center formation and somatic EZH2 mutations promote lymphoid transformation. Cancer Cell 2013;23:677-692.

75. Bodor C, et al. EZH2 mutations are frequent and represent an early event in follicular lymphoma. Blood 2013;122:3165-3168.

76. Morin $\mathrm{RD}$, et al. Somatic mutations altering EZH2 (Tyr641) in follicular and diffuse large B-cell lymphomas of germinal-center origin. Nat Genet 2010;42:181-185.

77. Sahasrabuddhe AA, Chen X, Chung F, Velusamy T, Lim MS, Elenitoba-Johnson KS. Oncogenic Y641 mutations in EZH2 prevent Jak2/beta-TrCPmediated degradation. Oncogene 2014. doi: 10. 1038/onc.2013.571.

78. Wu G, Xu G, Schulman BA, Jeffrey PD, Harper JW, Pavletich NP. Structure of a beta-TrCP1-Skp1-beta-catenin complex: destruction motif binding and lysine specificity of the SCF(beta-TrCP1) ubiquitin ligase. Mol Cell 2003;11:1445-1456.

79. Basso K, Dalla-Favera R. Roles of BCL6 in normal and transformed germinal center B cells. Immunol Rev 2012;247:172-183.

80. De Silva NS, Simonetti G, Heise N, Klein U. The diverse roles of IRF4 in late germinal center B-cell differentiation. Immunol Rev 2012;247:73-92.

81. Basso $\mathrm{K}$, et al. Integrated biochemical and computational approach identifies BCL6 direct target genes controlling multiple pathways in normal germinal center B cells. Blood 2010;115:975-984.

82. Ci W, et al. The BCL6 transcriptional program features repression of multiple oncogenes in primary B cells and is deregulated in DLBCL. Blood 2009;113:5536-5548.

83. Ranuncolo SM, Polo JM, Melnick A. BCL6 represses CHEK1 and suppresses DNA damage pathways in normal and malignant B-cells. Blood Cells Mol Dis 2008;41:95-99.

84. Ding BB, et al. Constitutively activated STAT3 promotes cell proliferation and survival in the activated B-cell subtype of diffuse large B-cell lymphomas. Blood 2008;111:1515-1523.

85. Ranuncolo SM, et al. Bcl-6 mediates the germinal center B cell phenotype and lymphomagenesis through transcriptional repression of the DNA-damage sensor ATR. Nat Immunol 2007;8:705-714. 
86. Tunyaplin C, Shaffer AL, Angelin-Duclos CD, Yu $\mathrm{X}$, Staudt LM, Calame KL. Direct repression of prdm1 by Bcl-6 inhibits plasmacytic differentiation. J Immunol 2004;173:11581165.

87. Angelin-Duclos C, Cattoretti G, Lin KI, Calame K. Commitment of B lymphocytes to a plasma cell fate is associated with Blimp-1 expression in vivo. J Immunol 2000;165:5462-5471.

88. Shaffer AL, Yu X, He Y, Boldrick J, Chan EP, Staudt LM. BCL-6 represses genes that function in lymphocyte differentiation, inflammation, and cell cycle control. Immunity 2000;13:199-212.

89. Pasqualucci L, et al. BCL-6 mutations in normal germinal center B cells: evidence of somatic hypermutation acting outside Ig loci. Proc Natl Acad Sci USA 1998;95:11816-11821.

90. Migliazza A, et al. Frequent somatic hypermutation of the $5^{\prime}$ noncoding region of the BCL6 gene in B-cell lymphoma. Proc Natl Acad Sci USA 1995;92:12520-12524.

91. Ye BH, Rao PH, Chaganti RS, Dalla-Favera R. Cloning of bcl-6, the locus involved in chromosome translocations affecting band 3q27 in B-cell lymphoma. Cancer Res 1993;53:27322735.

92. Baron BW, Nucifora G, McCabe N, Espinosa R 3rd, Le Beau MM, McKeithan TW. Identification of the gene associated with the recurring chromosomal translocations $\mathrm{t}(3 ; 14)$ (q27;q32) and $\mathrm{t}(3 ; 22)(\mathrm{q} 27 ; \mathrm{q} 11)$ in B-cell lymphomas. Proc Natl Acad Sci USA 1993;90:5262-5266.

93. Lobry C, Oh P, Mansour MR, Look AT, Aifantis I. Notch signaling: switching an oncogene to a tumor suppressor. Blood 2014;123:2451-2459.

94. Kiel MJ, et al. Whole-genome sequencing identifies recurrent somatic NOTCH2 mutations in splenic marginal zone lymphoma. J Exp Med 2012;209:1553-1565.

95. Rossi D, et al. The coding genome of splenic marginal zone lymphoma: activation of $\mathrm{NOTCH} 2$ and other pathways regulating marginal zone development. J Exp Med 2012;209:1537-1551.

96. Rosati E, et al. Constitutively activated Notch signaling is involved in survival and apoptosis resistance of B-CLL cells. Blood 2009; 113:856865.

97. Weng AP, et al. Activating mutations of NOTCH1 in human $\mathrm{T}$ cell acute lymphoblastic leukemia. Science 2004;306:269-271.

98. Klinakis A, et al. A novel tumour-suppressor function for the Notch pathway in myeloid leukaemia. Nature 2011;473:230-233.

99. Gasparini C, Celeghini C, Monasta L, Zauli G NF-kappaB pathways in hematological malignancies. Cell Mol Life Sci 2014;71:20832102.

100. Oeckinghaus A, Ghosh S. The NF-kappaB family of transcription factors and its regulation. Cold Spring Harb Perspect Biol 2009; 1:a000034

101. Keutgens A, Robert I, Viatour P, Chariot A. Deregulated NF-kappaB activity in haematological malignancies. Biochem Pharmacol 2006;72:1069-1080.

102. Milhollen MA, et al. MLN4924, a NEDD8-activating enzyme inhibitor, is active in diffuse large B-cell lymphoma models: rationale for treatment of NF-\{kappa\}B-dependent lymphoma. Blood 2010;116:1515-1523.

103. Busino L, Millman SE, Pagano M. SCF-mediated degradation of p100 (NF-kappaB2): mechanisms and relevance in multiple myeloma. Sci Signal 2012;5:pt14.

104. Busino L, et al. Fbxw7alpha- and GSK3-mediated degradation of p100 is a pro-survival mechanism in multiple myeloma. Nat Cell Biol 2012;14:375385

105. Gu Y, et al. MLN4924, an NAE inhibitor, suppresses AKT and mTOR signaling via upregulation of REDD1 in human myeloma cells. Blood 2014;123:3269-3276.

106. Rabut G, Peter M. Function and regulation of protein neddylation. 'Protein modifications: beyond the usual suspects' review series. EMBO Rep 2008;9:969-976.

107. Kanarek N, London N, Schueler-Furman O, Ben-Neriah Y. Ubiquitination and degradation of the inhibitors of NF-kappaB. Cold Spring Harb Perspect Biol 2010;2:a000166.

108. Amir RE, Haecker H, Karin M, Ciechanover A. Mechanism of processing of the NF-kappa B2 p100 precursor: identification of the specific polyubiquitin chain-anchoring lysine residue and analysis of the role of NEDD8-modification on the $\mathrm{SCF}$ (beta- $\operatorname{TrCP}$ ) ubiquitin ligase. Oncogene 2004;23:2540-2547.

109. Cohen S, Achbert-Weiner H, Ciechanover A. Dua effects of IkappaB kinase beta-mediated phosphorylation on p105 Fate: SCF (beta-TrCP)-dependent degradation and SCF (beta-TrCP)-independent processing. Mol Cell Biol 2004;24:475-486.

110. Orian A, et al. SCF(beta) (-TrCP) ubiquitin ligase-mediated processing of NF-kappaB p105 requires phosphorylation of its $\mathrm{C}$-terminus by IkappaB kinase. EMBO J 2000;19:2580-2591.

111. Pelengaris S, Khan M, Evan G. c-MYC: more than just a matter of life and death. Nat Rev Cancer 2002;2:764-776.

112. Bahram F, von der Lehr N, Cetinkaya C, Larsson LG. c-Myc hot spot mutations in lymphomas result in inefficient ubiquitination and decreased proteasome-mediated turnover. Blood 2000;95:2104-2110.

113. Gregory MA, Hann SR. c-Myc proteolysis by the ubiquitin-proteasome pathway: stabilization of c-Myc in Burkitt's lymphoma cells. Mol Cell Biol 2000;20:2423-2435.

114. Diefenbacher ME, et al. The deubiquitinase USP2 8 controls intestinal homeostasis and promotes colorectal cancer. J Clin Invest 2014;124:3407-3418.

115. Schwickart M, et al. Deubiquitinase USP9X stabilizes MCL1 and promotes tumour cell survival. Nature 2010;463:103-107.

116. Wuilleme-Toumi S, et al. Mcl-1 is overexpressed in multiple myeloma and associated with relapse and shorter survival. Leukemia 2005;19:1248-1252.

117. Kaufmann SH, et al. Elevated expression of the apoptotic regulator $\mathrm{Mcl}-1$ at the time of leukemic relapse. Blood 1998;91:991-1000.

118. Park Y, Jin HS, Liu YC. Regulation of T cell function by the ubiquitin-specific protease
USP9X via modulating the Carma1-Bcl10-Malt complex. Proc Natl Acad Sci USA 2013;110:9433-9438.

119. Peng Z, et al. Degrasyn-like symmetrical compounds: possible therapeutic agents for multiple myeloma (MM-I). Bioorg Med Chem 2014;22:1450-1458

120. Bignell GR, et al. Identification of the familial cylindromatosis tumour-suppressor gene. Nat Genet 2000;25:160-165.

121. Blake PW, Toro JR. Update of cylindromatosis gene (CYLD) mutations in Brooke-Spiegler syndrome: novel insights into the role of deubiquitination in cell signaling. Hum Mutat 2009;30:1025-1036

122. Massoumi R, Paus R. Cylindromatosis and the CYLD gene: new lessons on the molecular principles of epithelial growth control. BioEssays 2007;29:1203-1214

123. Espinosa L, et al. The Notch/Hes1 pathway sustains NF-kappaB activation through CYLD repression in $\mathrm{T}$ cell leukemia. Cancer Cell 2010;18:268-281.

124. Ohshima K, et al. Chromosome 16q deletion and loss of E-cadherin expression in Hodgkin and Reed-Sternberg cells. Int J Cancer 2001;92:678682.

125. Sun SC. CYLD: a tumor suppressor deubiquitinase regulating NF-kappaB activation and diverse biological processes. Cell Death Differ 2010; 17:25-34.

126. Sun SC. Deubiquitylation and regulation of the immune response. Nat Rev Immunol 2008;8:501-511.

127. Courtois G. Tumor suppressor CYLD: negative regulation of NF-kappaB signaling and more. Cell Mol Life Sci 2008;65:1123-1132.

128. Wickstrom SA, Masoumi KC, Khochbin S, Fassler R, Massoumi R. CYLD negatively regulates cell-cycle progression by inactivating HDAC6 and increasing the levels of acetylated tubulin. EMBO J 2010;29:131-144.

129. Stegmeier F, Sowa ME, Nalepa G, Gygi SP, Harper JW, Elledge SJ. The tumor suppressor CYLD regulates entry into mitosis. Proc Natl Acad Sci USA 2007;104:8869-8874.

130. Li D, et al. CYLD coordinates with EB1 to regulate microtubule dynamics and cell migration. Cell Cycle 2014;13:974-983.

131. Gao J, et al. The tumor suppressor CYLD regulates microtubule dynamics and plays a role in cell migration. J Biol Chem 2008;283:8802-8809.

132. Ma A, Malynn BA. A20: linking a complex regulator of ubiquitylation to immunity and human disease. Nat Rev Immunol 2012;12:774 785.

133. Schmitz R, et al. TNFAIP3 (A20) is a tumor suppressor gene in Hodgkin lymphoma and primary mediastinal B cell lymphoma. J Exp Med 2009;206:981-989.

134. Compagno $\mathrm{M}$, et al. Mutations of multiple genes cause deregulation of NF-kappaB in diffuse large B-cell lymphoma. Nature 2009;459:717-721.

135. Kato M, et al. Frequent inactivation of A20 in B-cell lymphomas. Nature 2009;459:712-716

136. Novak U, et al. The NF-\{kappa\}B negative regulator TNFAIP3 (A20) is inactivated by 
somatic mutations and genomic deletions in marginal zone lymphomas. Blood 2009;113:4918-4921.

137. Chanudet E, et al. A20 is targeted by promoter methylation, deletion and inactivating mutation in MALT lymphoma. Leukemia 2010;24:483487.

138. Honma K, et al. TNFAIP3/A20 functions as a novel tumor suppressor gene in several subtypes of non-Hodgkin lymphomas. Blood 2009;114:2467-2475.

139. Nomoto J, et al. Deletion of the TNFAIP3/A20 gene detected by FICTION analysis in classical Hodgkin lymphoma. BMC Cancer 2012;12:457.

140. Zhu L, et al. Characteristics of A20 gene polymorphisms in T-cell acute lymphocytic leukemia. Hematology 2014. [Epub ahead of print].

141. Braun FC, et al. Tumor suppressor TNFAIP3 (A20) is frequently deleted in Sezary syndrome. Leukemia 2011;25:1494-1501.

142. Shao L, et al. A20 restricts wnt signaling in intestinal epithelial cells and suppresses colon carcinogenesis. PLoS ONE 2013;8:e62223.

143. Shi CS, Kehrl JH. TRAF6 and A20 regulate lysine 63-linked ubiquitination of Beclin-1 to control TLR4-induced autophagy. Sci Signal 2010;3:ra42.

144. Lin $\mathrm{R}$, et al. Negative regulation of the retinoic acid-inducible gene I-induced antiviral state by the ubiquitin-editing protein A20. J Biol Chem 2006;281:2095-2103.

145. Saitoh T, et al. A20 is a negative regulator of IFN regulatory factor 3 signaling. J Immunol 2005; 174:1507-1512.

146. Catrysse L, Vereecke L, Beyaert R, van Loo G. A20 in inflammation and autoimmunity. Trends Immunol 2014;35:22-31.

147. Shimbara N, et al. Regulation of gene expression of proteasomes (multi-protease complexes) during growth and differentiation of human hematopoietic cells. J Biol Chem 1992;267:18100-18109.

148. Kumatori A, et al. Abnormally high expression of proteasomes in human leukemic cells. Proc Natl Acad Sci USA 1990;87:7071-7075.

149. Delic J, et al. The proteasome inhibitor lactacystin induces apoptosis and sensitizes chemo- and radioresistant human chronic lymphocytic leukaemia lymphocytes to
TNF-alpha-initiated apoptosis. Br J Cancer 1998;77:1103-1107.

150. Masdehors P, Merle-Beral H, Magdelenat H, Delic J. Ubiquitin-proteasome system and increased sensitivity of B-CLL lymphocytes to apoptotic death activation. Leuk Lymphoma 2000;38:499504.

151. O'Connor OA, et al. Phase II clinical experience with the novel proteasome inhibitor bortezomib in patients with indolent non-Hodgkin's lymphoma and mantle cell lymphoma. J Clin Oncol 2005;23:676-684.

152. Goy A, et al. Phase II study of proteasome inhibitor bortezomib in relapsed or refractory B-cell non-Hodgkin's lymphoma. J Clin Oncol 2005;23:667-675.

153. Coux O, Tanaka K, Goldberg AL. Structure and functions of the $20 \mathrm{~S}$ and $26 \mathrm{~S}$ proteasomes. Annu Rev Biochem 1996;65:801-847.

154. Richardson PG, et al. Frequency, characteristics, and reversibility of peripheral neuropathy during treatment of advanced multiple myeloma with bortezomib. J Clin Oncol 2006;24:3113-3120.

155. Kuhn DJ, et al. Potent activity of carfilzomib, a novel, irreversible inhibitor of the ubiquitin-proteasome pathway, against preclinical models of multiple myeloma. Blood 2007;110:3281-3290

156. Macherla VR, et al. Structure-activity relationship studies of salinosporamide A (NPI-0052), a novel marine derived proteasome inhibitor. J Med Chem 2005;48:3684-3687.

157. Miller CP, et al. NPI-0052, a novel proteasome inhibitor, induces caspase- 8 and ROS-dependent apoptosis alone and in combination with HDAC inhibitors in leukemia cells. Blood 2007; 110:267-277.

158. Millward M, et al. Phase 1 clinical trial of the novel proteasome inhibitor marizomib with the histone deacetylase inhibitor vorinostat in patients with melanoma, pancreatic and lung cancer based on in vitro assessments of the combination. Invest New Drugs 2012;30:23032317.

159. Richardson PG, et al. Phase 1 study of twice-weekly dosing of investigational oral proteasome inhibitor ixazomib in patients with relapsed and/or refractory multiple myeloma. Blood 2014;124:1038-1046.
160. Chauhan D, et al. A novel orally active proteasome inhibitor ONX 0912 triggers in vitro and in vivo cytotoxicity in multiple myeloma. Blood 2010;116:4906-4915.

161. Piva R, et al. CEP-18770: a novel, orally active proteasome inhibitor with a tumor-selective pharmacologic profile competitive with bortezomib. Blood 2008;111:2765-2775.

162. Dorsey BD, et al. Discovery of a potent, selective, and orally active proteasome inhibitor for the treatment of cancer. J Med Chem 2008;51:10681072.

163. Kapuria V, et al. A novel small molecule deubiquitinase inhibitor blocks Jak2 signaling through Jak2 ubiquitination. Cell Signal 2011;23:2076-2085.

164. Kapuria V, Peterson LF, Fang D, Bornmann WG, Talpaz M, Donato NJ. Deubiquitinase inhibition by small-molecule WP1130 triggers aggresome formation and tumor cell apoptosis. Cancer Res 2010;70:9265-9276.

165. Jeromin S, et al. SF3B1 mutations correlated to cytogenetics and mutations in NOTCH1, FBXW7, MYD88, XPO1 and TP53 in 1160 untreated CLL patients. Leukemia 2014;28:108-117.

166. Traina F, et al. Single nucleotide polymorphism array lesions, TET2, DNMT3A, ASXL1 and CBL mutations are present in systemic mastocytosis. PLoS ONE 2012;7:e43090.

167. Shiba N, et al. CBL mutation in chronic myelomonocytic leukemia secondary to familial platelet disorder with propensity to develop acute myeloid leukemia (FPD/AML). Blood 2012;119:2612-2614.

168. Tefferi A. Novel mutations and their functional and clinical relevance in myeloproliferative neoplasms: JAK2, MPL, TET2, ASXL1, CBL, IDH and IKZF1. Leukemia 2010;24:1128-1138.

169. Muramatsu H, et al. Mutations of an E3 ubiquitin ligase c-Cbl but not TET2 mutations are pathogenic in juvenile myelomonocytic leukemia. Blood 2010;115:1969-1975.

170. Schmidt A, et al. Rare occurrence of biallelic CYLD gene mutations in classical Hodgkin lymphoma. Genes Chromosom Cancer 2010;49:803-809.

171. Hymowitz SG, Wertz IE. A20: from ubiquitin editing to tumour suppression. Nat Rev Cancer 2010;10:332-341. 